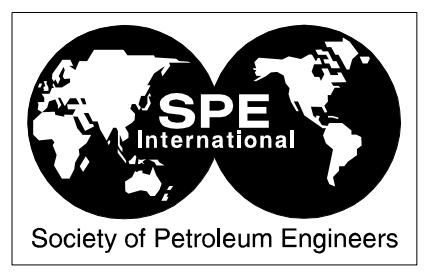

\title{
Run Life Enlargement Methodology for Ball-and-Seat Check Valves Used in Artificial Lift Pumping Units
}

S. Zarea, Universidad Simon Bolivar, L. Rojas-Solorzano, Universidad Simon Bolivar, F. Kabboul, PDVSA Servicios

\begin{abstract}
Copyright 1999, Society of Petroleum Engineers Inc.
This paper was prepared for presentation at the 1999 SPE Latin American and Caribbean Petroleum Engineering Conference held in Caracas, Venezuela, 21-23 April 1999.

This paper was selected for presentation by an SPE Program Committee following review of information contained in an abstract submitted by the author(s). Contents of the paper, as presented, have not been reviewed by the Society of Petroleum Engineers and are subject to correction by the author(s). The material, as presented, does not necessarily reflect any position of the Society of Petroleum Engineers, its officers, or members. Papers presented at SPE meetings are subject to publication review by Editorial Committees of the Society of SPE meetings are subject to publication review by Editorial Committees of the Society of
Petroleum Engineers. Electronic reproduction, distribution, or storage of any part of this paper for commercial purposes without the written consent of the Society of Petroleum Engineers is prohibited. Permission to reproduce in print is restricted to an abstract of not more than 300 words; illustrations may not be copied. The abstract must contain conspicuous acknowledgment of where and by whom the paper was presented. Write Librarian, SPE, P.O. Box 833836, Richardson, TX 75083-3836, U.S.A., fax 01-972-952-9435.
\end{abstract}

\section{Abstract}

Experiments are performed to evaluate the leakage vs. pressure drop, wear and fluid properties, in ball-and-seat valves used in pumping units for artificial oil production. The test facility is constructed to evaluate the operation of several valve sizes, using water, oil and air, subjected to pressure drops up to 5000 psig. Results demonstrated that the currently accepted API vacuum test might be too severe and that more realistic tests may lead to substantial savings in valve replacements. Experimental results in dimensional and dimensionless form are presented, using a new similitude criterion.

\section{Introduction}

The oil industry spends a large amount of money in maintenance of production equipment. Part of the maintenance activity corresponds to replacement of worn parts by new ones. One of the parts, according to current API quality control tests, with high frequency of replacement within the mechanical pump unit used in artificial lift method is the ball-and-seat check valve. Figure 1 shows the suction of the mechanical pump including the traveling and standing check valves ${ }^{1,2}$. The operation of the set of valves is as follows: when the pump rod ascends, the traveling valve is closed pushing the fluid up the well, and the standing valve opens, letting the oil into the valve-to-valve section; when the pump rod descends, the traveling valve lets the fluid into the upper section and the fixed valve remains closed under the weight of the fluid ${ }^{3}$.
This paper reports the study of the leakage in used balland-seat check valves while in closed position for quality control purposes. A new device and test methodology is here proposed and examined.

The results from this new test equipment are compared to currently accepted quality control vacuum tests. The proposed methodology is intended to be more realistic and therefore, will lead to more accurate diagnostics before deciding whether or not a valve should be replaced.

The currently accepted test, denominated hereafter "vacuum test" consists in placing the valve (seat and ball) on a flat surface with a small orifice in the center and then, create a controlled vacuum under the ball to leak-proof the valve. While testing, the upstream side of the valve is maintained at atmospheric pressure. Therefore, the larger pressure drop obtained with this device always will be smaller than 14.7 psi.

The equipment proposed in this work uses either air or liquids (water and oil) as working fluid in order to reproduce realistic field fluid properties. The test is performed applying the fluid pressure upstream the valve, giving a larger range in pressure drop than obtained in the vacuum test.

Tests are performed on new and used-discarded valves. Results obtained from the new methodology on new valves confirm the reliability of the new test device. Results obtained for used-discarded valves demonstrates that currently rejected valves may continue working according to the low-leakage level found and therefore, potential savings in maintenance expenses and production costs might be obtained.

\section{Proposed Test Equipment and Methodology}

The design of the test equipment had several constraints: (a) to resist pressures up to 5000 psig; (b) to work with liquids and air; (c) to handle several sizes of valves; (d) to be easy to operate, maintain and transport.

Test Equipment. Figures $2 \mathrm{a}$ and $2 \mathrm{~b}$ show the test equipment made for liquids and air, respectively ${ }^{3}$.

The equipment for liquids consists in a piston hand pump with the suction line connected to the liquid reservoir; the discharge line is connected to the carbon steel cell with the valve to be tested in the interior of it ${ }^{4,5}$. The cell discharges to a plexiglass container to account for the leaked liquid from 
the valve during the test. The maximum pressure allowed by the pump-pipe-cell system is 5000 psig.

The equipment for air consists in a tank with air supplied by a compressor. The air tank discharges to the same carbon steel cell used in the liquid system. The leakage measurement is made through the water displacement in the plexiglass container hermetically connected to the cell, downstream the valve. This air system permits pressures up to $100 \mathrm{psig}$.

Measurement of Experimental Parameters. The fluid pressure within the test cell was measured using a strain gauge pressure sensor with digital output, $\pm 1 \mathrm{psi}$ accurate.

The liquid (water and oil) leakage was measured with a calibrated reservoir, $\pm 0.1 \mathrm{ml}$ accurate, while for air the leakage measurement was $\pm 10 \mathrm{ml}$ accurate.

The ball and seat mean roughness was measured with a roundness-roughness meter, $0.01 \mu \mathrm{m}$ accurate.

The ball and seat sizes were measured with a Vernier caliper, $0.01 \mathrm{~mm}$ accurate.

The time was measured with a digital chronometer, 0.01 sec. accurate.

The error analysis leads to a maximum total error in the leakage measurement of $2 \mathrm{ml} / \mathrm{h}$ for liquids and $200 \mathrm{ml} / \mathrm{h}$ for air. These quantities, though looking large, are quite small compared to the effective leakage measurements, as will be shown later.

Test Methodology. The design of the testing procedure had three major requirements to accomplish: (a) to produce reliable results; (b) to reproduce, in a realistic manner, the static condition of the valve; and (c) to be relatively fast to perform.

Four working fluids were chosen, ranging from low viscosity (air), medium viscosity (water) and high viscosity (two types of oil: $34.24 \mathrm{cp}$ and $262.86 \mathrm{cp}$ ).

The general procedure of experimentation was based firstly on selecting the working fluid; secondly, for a valve seat of a given diameter and roughness, several ball roughness were tested. The procedure was repeated for up to four different seat roughness and then for the other three fluids.

In all the experiments with water and oil, the leakage was measured by setting the pressure up at: $0,10,20,30,50,80$, $100,200,500,1000,2000$ and 3000 psig and measuring the volume of leaked liquid after 3 minutes. The experiments with air were performed with pressures of $1,5,10,20,30,50$, and 100 psig and measuring the time it took until a $120 \mathrm{ml}$ leakage was obtained.

The experimental scheme is shown in Fig. 3.

\section{Experimental Results}

Although, tests were performed with brand new and useddiscarded valves, results presented in this section correspond to the second case in order to compare this test with the vacuum test.
Figure 4 shows a typical case of air tests. This case corresponds to a ball and seat diameter-roughness of 34.925 $\mathrm{mm}-0.1747 \mu \mathrm{m}$ and $25 \mathrm{~mm}-0.843 \mu \mathrm{m}$, respectively.

Figure 5 depicts a typical case of water tests and Fig. 6 shows one of the oil test cases.

The comparison between the water and oil leakage is summarized in Fig. 6.

In order to generalize the experimental results, a set of non-dimensional parameters were chosen after a dimensional analysis ${ }^{6}$. The flow leakage through the tested valves is characterized by the following eight parameters: $\mathrm{Q}, \Delta \mathrm{p}, \varepsilon_{\mathrm{a}}, \varepsilon_{\mathrm{b}}$, $\rho, \mu, D_{a}$ and $D_{b}$. Applying Buckingham's Theorem, the following dimensionless parameters are obtained:

$$
\pi_{1}=\frac{\rho \mathrm{Q}}{\mu \mathrm{D}_{\mathrm{b}}} \quad ; \pi_{2}=\frac{\rho \Delta \mathrm{pD}_{\mathrm{b}}^{2}}{\mu^{2}} ; \pi_{3}=\frac{\varepsilon_{\mathrm{b}}+\varepsilon_{\mathrm{a}}}{\mathrm{D}_{\mathrm{a}}}
$$

which allows to write the dimensionless flow leakage as

$$
\frac{\rho Q}{\mu D_{b}}=f\left(\frac{\rho \Delta p D_{b}^{2}}{\mu^{2}}, \frac{E}{D_{b}}\right)
$$

The first parameter, $\pi_{1}$, represents the flow leakage through the valve seat, or else, the Reynolds number for the leakage flow, i.e.,

$$
\mathrm{R}_{\mathrm{e}_{\mathrm{L}}}=\frac{\rho \mathrm{Q}}{\mu \mathrm{D}_{\mathrm{b}}}=\frac{\pi}{4} \frac{\mathrm{D}_{\mathrm{b}}^{2} \mathrm{~V}}{v \mathrm{D}_{\mathrm{b}}}=\frac{\pi}{4} \mathrm{R}_{\mathrm{e}}
$$

where: $\mathrm{R}_{\mathrm{e}}=\frac{\mathrm{D}_{\mathrm{b}} \mathrm{V}}{\mathrm{v}}$

The second parameter, $\pi_{2}$, defines a new dimensionless number:

$$
\begin{gathered}
\mathrm{R}_{\mathrm{e}_{\mathrm{L}}}=\frac{\rho \mathrm{Q}}{\mu \mathrm{D}_{\mathrm{b}}}=\frac{\pi}{4} \frac{\mathrm{D}_{\mathrm{b}}^{2} \mathrm{~V}}{v \mathrm{D}_{\mathrm{b}}}=\frac{\pi}{4} \mathrm{R}_{\mathrm{e}} \\
\mathrm{KRZ}=\frac{\rho \Delta \mathrm{pD} \mathrm{b}_{\mathrm{b}}^{2}}{\mu^{2}}=\frac{\Delta \mathrm{p}}{\rho \mathrm{V}^{2}}\left(\frac{\mathrm{D}_{\mathrm{b}} \mathrm{V}}{\nu}\right)^{2}=\mathrm{E}_{\mathrm{u}} \mathrm{R}_{\mathrm{e}}^{2}
\end{gathered}
$$

where: $\mathrm{E}_{\mathrm{u}}=\frac{\Delta \mathrm{p}}{\rho \mathrm{V}^{2}}$

In this case, KRZ (Kabboul-Rojas-Zarea) number represents the dimensionless pressure drop in the valve.

The non-dimensional parameters and their physical meaning are: 


$$
\begin{aligned}
& \frac{\rho \mathrm{Q}}{\mu \mathrm{D}_{\mathrm{b}}}=\text { non-dimensional leak flow } \\
& \frac{\rho \Delta \mathrm{p} \mathrm{D}_{\mathrm{b}}^{2}}{\mu^{2}}=\text { non-dimensional pressure drop } \\
& \frac{\varepsilon_{\mathrm{a}}+\varepsilon_{\mathrm{b}}}{\mathrm{D}_{\mathrm{a}}}=\text { relative roughness of the valve }
\end{aligned}
$$

The errors reported when calculating these nondimensional parameters are:

$$
\begin{aligned}
& \text { Error }\left(\frac{\rho Q}{\mu D_{b}}\right)= \pm 0.019 \\
& \operatorname{Error}\left(\frac{\varepsilon_{a}+\varepsilon_{b}}{D_{a}}\right)= \pm 8.8 \times 10^{-7}
\end{aligned}
$$

The non-dimensional results collapsed very well onto a single set of curves, indicating the appropriate selection of dimensional parameters from the dimensional analysis. Figure 7 shows the results of the tests in terms of the nondimensional parameters.

\section{Analysis of Results}

The results of the experiments demonstrated clear dependency among the fluid viscosity, pressure drop mean roughness, and the valve leakage. This dependency is explained below.

Influence of the Working Fluid. For the air tests, the pressure drop was limited to $100 \mathrm{psi}$. In this case, the valve leakage grows with the pressure drop and the mean roughness. For example, a check valve with roughness five times greater than another valve, will present three times more fluid leakage than the smoother valve.

For liquid tests, it is observed that under the same pressure drop and mean roughness conditions the valve leakage diminishes as the fluid viscosity grows. It is noticed that the liquid leakage increases with the pressure drop until a critical value of the pressure; for larger pressure drops, the valve leakage decreases steeply. The value of that critical pressure depends on the valve mean roughness.

The results show that though the valve leakage and the sealant surface between the ball and seat are proportional to the pressure drop, for pressure drops lower than a critical value (which depends on the fluid viscosity), the leakage effect domains the sealant effect; while for larger pressure drops, the leakage effect becomes smaller.

Influence of the Pressure Drop. As mentioned in the previous paragraph, the fluid leakage increases with the pressure drop until the critical pressure is reached. For pressure drops larger than the critical pressure, the effect is inverted and the leakage diminishes with the pressure drop.

This effect obeys to the need of a minimum pressure to have an appropriate contact or sealant surface between the ball and seat.

Influence of the Roughness. It is noticed that the fluid leakage is proportional to the mean roughness of the valve. However, from the experimental observations, it was noticed that the influence of the seat roughness was larger than the influence of the ball roughness. This obeys to the fact that the valve seat is made of a harder material than the ball and therefore, the seat resists larger stress without appreciable deformation when large pressure drops are applied to the valve $^{7}$.

Interpretation of the Non-dimensional Plot. The main objective of this plot is to predict the fluid leakage in balland-seat valves with different mean roughness, working with any type of fluid and subject to certain pressure drop.

From Fig. 7, it is noticed that the non-dimensional leakage flow is proportional to the non-dimensional mean roughness. The non-dimensional leakage is proportional to the nondimensional pressure drop under the critical pressure (nondimensional); for non-dimensional pressures larger than the critical pressure, the leakage is inversely proportional to the pressure drops, as it was noticed in the dimensional plots.

Comparison with Vacuum Test. The results reported in this paper corresponds to check valves that have been discarded by the vacuum test. Results from the high viscosity oil test, show that fluid leakage observed under even severe pressure drops and large mean roughness values was quite negligible compared to the typical amount of daily oil production in a single oil well ( $80 \mathrm{bpd}-1600 \mathrm{bpd})$.

\section{Conclusions and Recommendations}

A new test equipment and methodology have been developed and results have been presented to compare to current vacuum tests. From the results of this investigation it is concluded that:

1. The currently accepted vacuum test is too severe to evaluate ball-and-seat check valves in use. It is recommended to perform the vacuum test only on brand new valves as an appropriate quality control test under such a condition.

2. Based on the amount of fluid leakage, it might be stated that a large amount of valves currently discarded are still in capacity to be used. The amount of time that can be added to those valves will depend on the degree of damage (mean roughness) that they present. 
3. There is a direct relationship between the valve roughness, the pressure drop and the fluid leakage. That relationship develops in the following way:

(a) a larger fluid viscosity leads to a smaller fluid leakage

(b) a larger pressure drop leads to a larger fluid leakage until a critical pressure is reached; afterwards, a larger pressure drop leads to smaller fluid leakage.

4. The test facility and methodology here proposed are highly reliable.

5. It is advisable to substitute the current test equipment and methodology by a new system capable to reproduce more realistic features found in the field.

6. It would be worthy to perform an investigation to establish a relationship between the amount of life cycles developed by a valve and the degree of wear or mean roughness found in the ball and seat.

\section{Nomenclature}

$\mathrm{D}_{\mathrm{b}}$ : valve diameter

$\mathrm{D}_{\mathrm{a}}$ : seat diameter

Q: Flow leakage through valve

$\Delta \mathrm{p}$ : Pressure drop acting on valve

$\varepsilon_{\mathrm{a}}$ : Seat roughness

$\varepsilon_{\mathrm{b}}$ : Ball roughness

E: Valve roughness $\left(\varepsilon_{\mathrm{a}}+\varepsilon_{\mathrm{b}}\right)$

$\rho$ : Fluid density

$\mu, v$ : Dynamic and kinematic viscosity, respectively

$\mathrm{V}$ : Mean velocity of leakage flow

$\mathrm{R}_{\mathrm{e}_{\mathrm{L}}}$ : Reynolds number based on leakage flow

$\mathrm{E}_{\mathrm{u}}$ : Euler number

KRZ: Kabboul-Rojas-Zarea dimensionless number

\section{Acknowledgments}

We want to thank Georges Kabboul, M.E., for his valuable comments and suggestions. We also want to thank Dr. Amnon Vadasz, Marcelo Reyna, M.E., and José Ercolino, M.E., of PDVSA-Intevep for proposing the topic and their recommendations and comments along this investigation.

\section{References}

1. Vadasz, A.: Bombas de Subsuelo en Venezuela -Estado de Avanzada-, INTEVEP S.A. (1984).

2. Mabie, H. \& Ocvirk, F.: Mechanisms and Dynamics of Machinery, New York, John Wiley and Sons. (1963).

3. Kabboul, F., and Rojas-Solórzano L.: Estudio Experimental y Mejoramiento Hidráulico de Válvulas de Medianas Dimensiones, Dissertation as a partial requirement to obtain the Eng. Degree at Universidad Simón Bolívar, adviser Prof. S. Zarea, Caracas (1984).

4. Shigley, J.: Mechanical Engineering Design, New York, Mc Graw-Hill. (1972).
5. Singer, F and Pytel, A.: Resistencia de Materiales, Mexico, Harla. (1982).

6. Streeter, V. and Wylie, B.: Mecánica de los Fluidos, Mexico, Mc Graw-Hill. (1979).

7. Streeter, V.: Control Wear Handbook, John Wiley \& Sons, New York. 


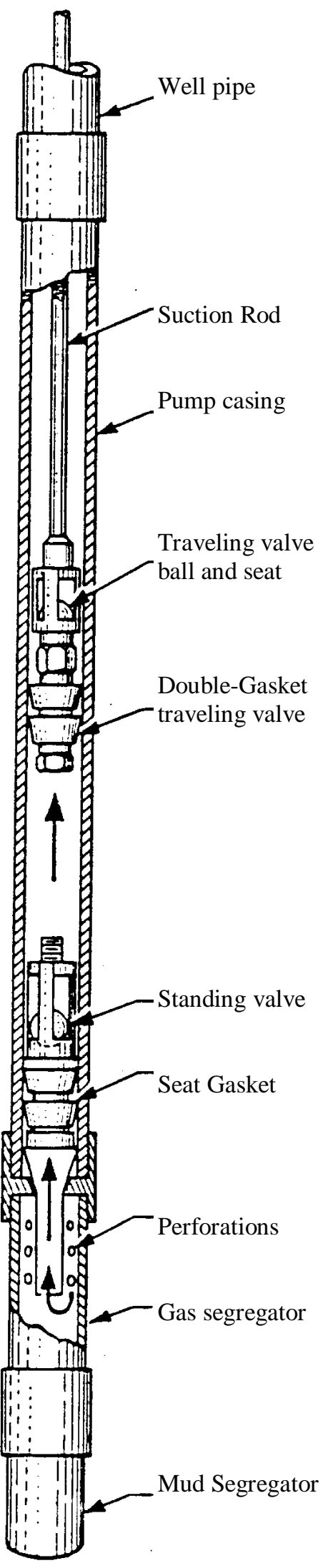

ball-and-seat valves.

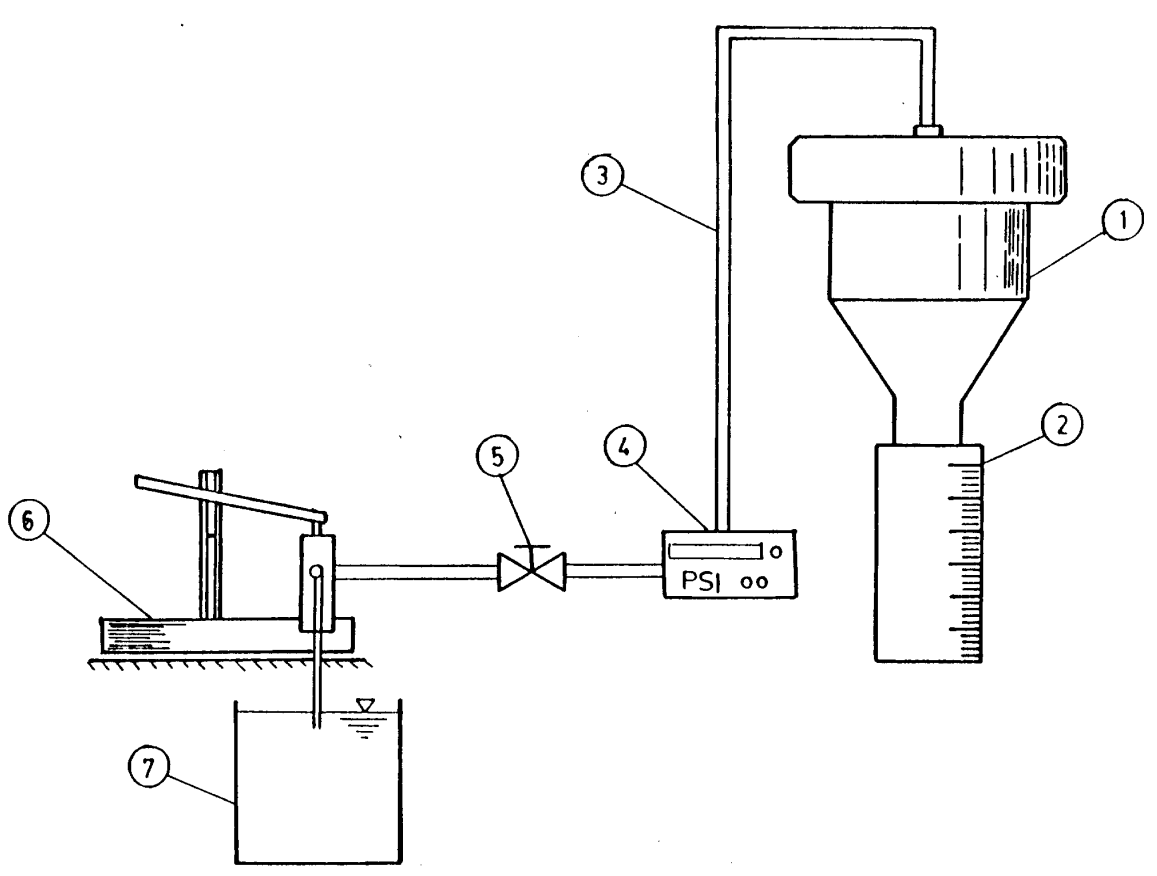

Fig. 2a. Sketch of test equipment for experiments with water and/or oil.

1. Pressure cell

2. Plexi-glass cylinder

3. 5000 psi tubing

4. Manometer or pressure gauge

5. Control valve

6. Hand piston pump

7. Reservoir

Fig. 1. Suction pipeline showing the standing and traveling 


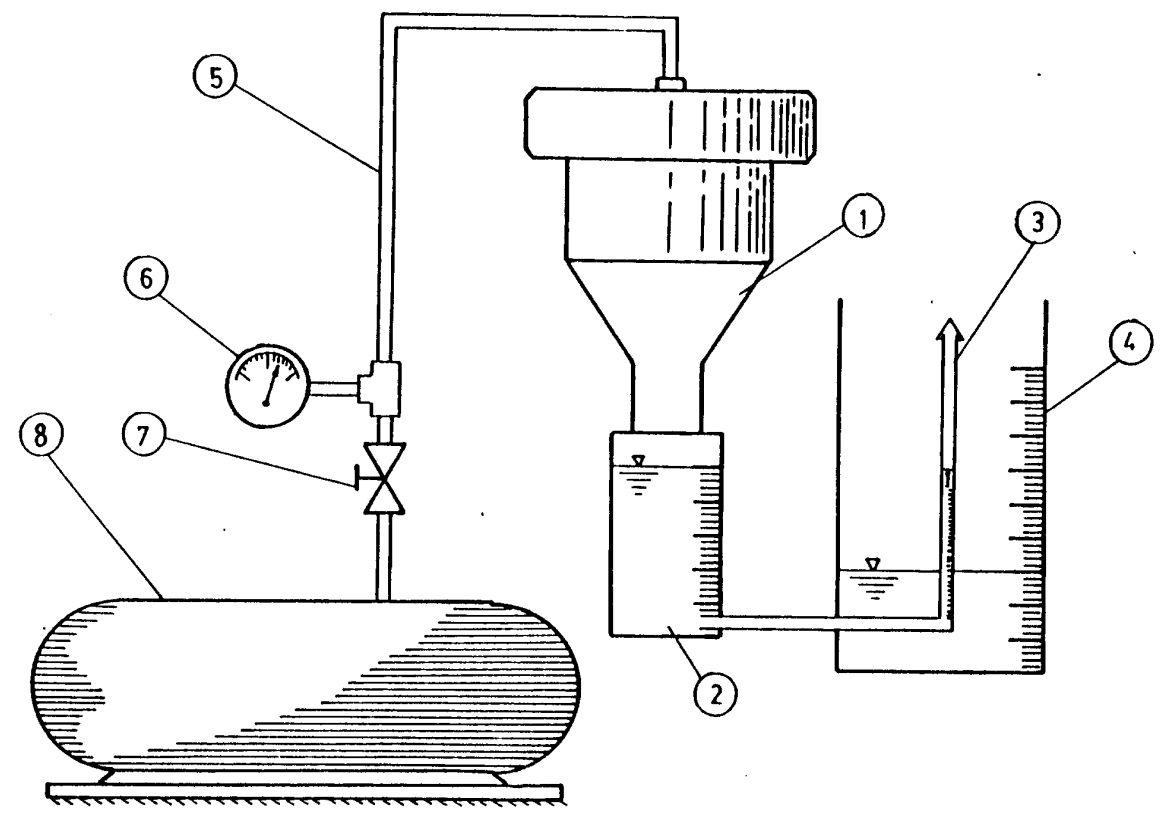

Fig. 2b. Sketch of test equipment for experiments with air.

1. Pressure cell

2. Plexi-glass cylinder

3. Chimney

4. Reservoir discharge

5. Tubing $1 / 4$

6. Manometer or pressure gauge

7. Control valve

8. Compressor

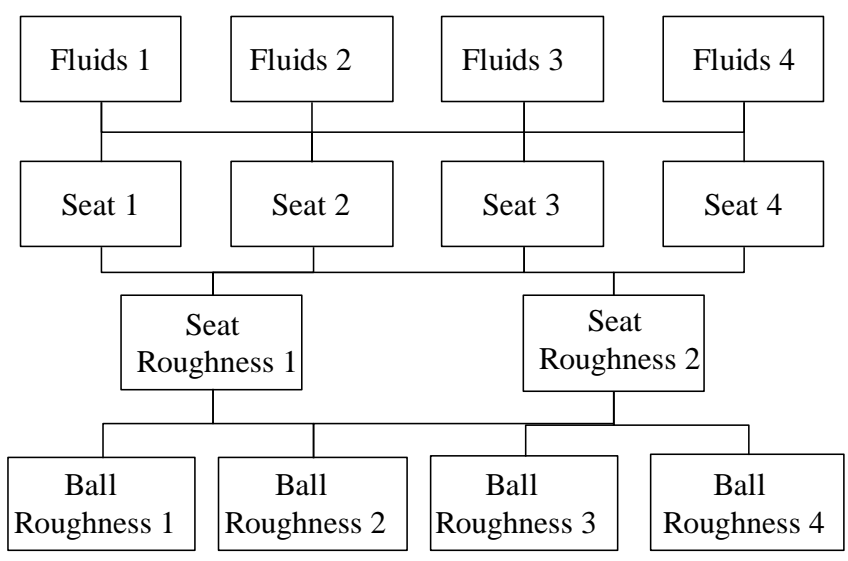

Fig. 3. Plan of experiments. 


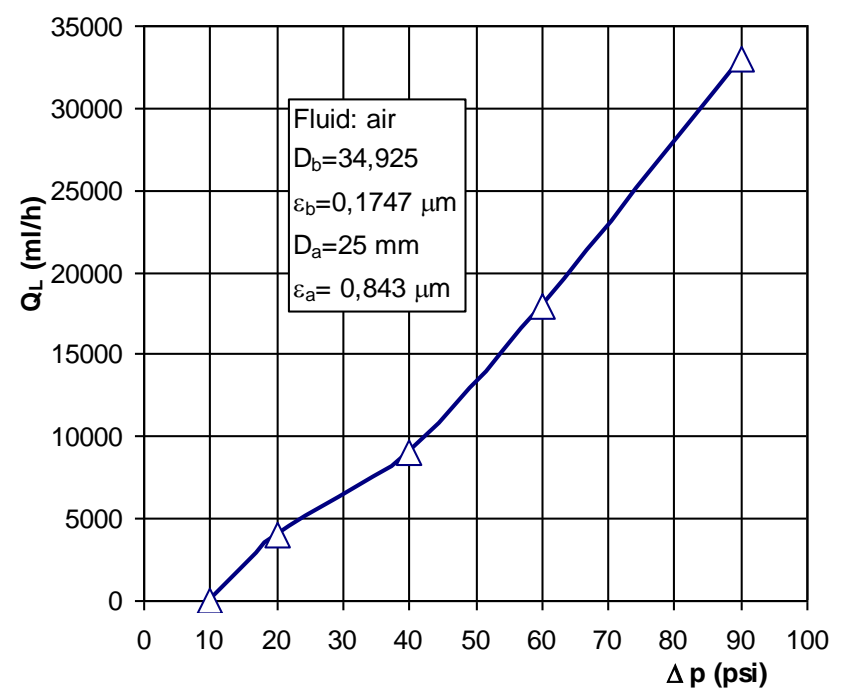

Fig. 4. Variation of air leakage flow through the ball-and-seat valve vs. pressure drop.

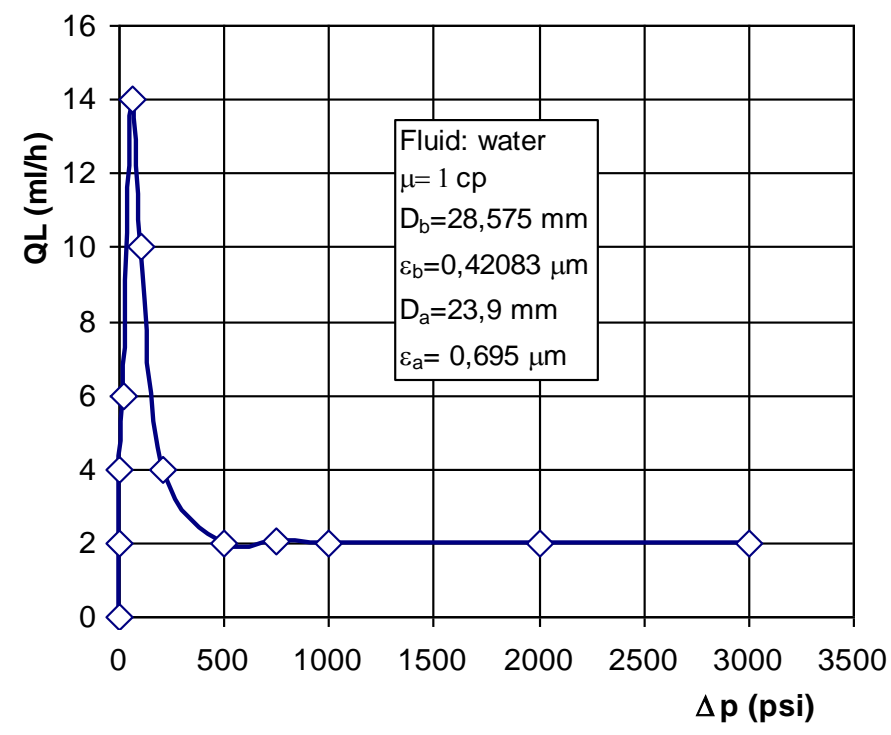

Fig. 5. Variation of water leakage flow through the ball-andseat valve vs. pressure drop.

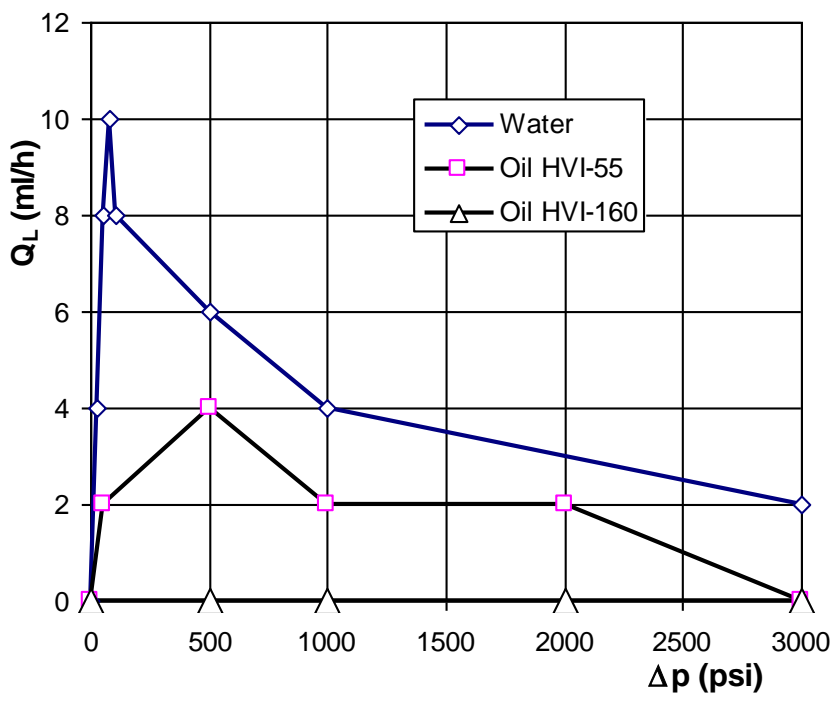

Fig. 6. Variation of leakage flow through the ball-and-seat valve vs. pressure drop for three different fluids.

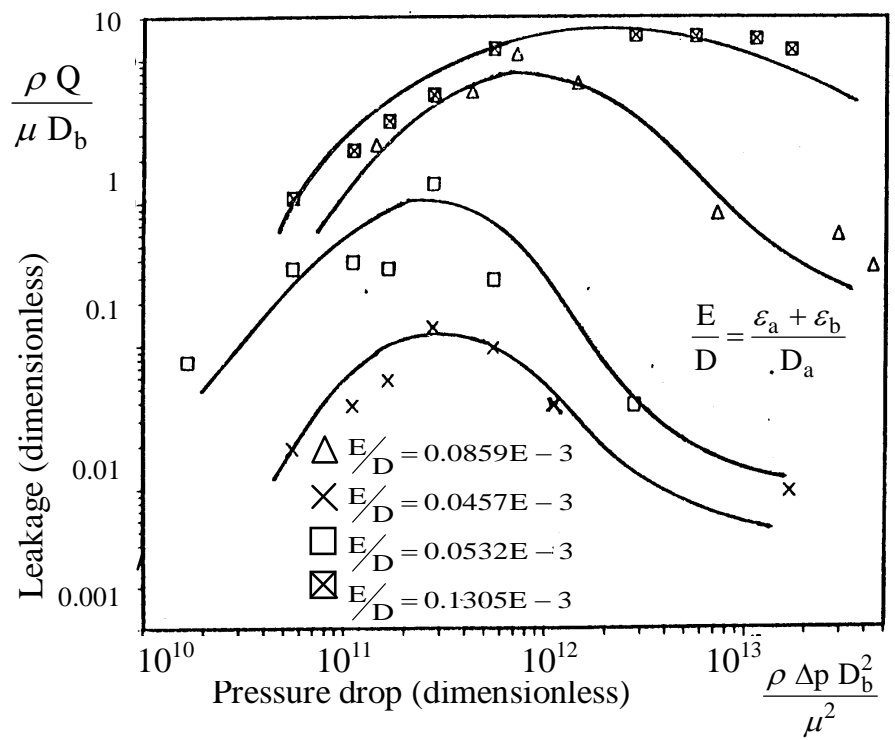

Fig. 7. Variation of dimensionless leakage flow vs. dimensionless pressure 